\title{
SLUDGE FILTERABILITY AND DEWATERABILITY IN A MEMBRANE BIOREACTOR FOR MUNICIPAL WASTEWATER TREATMENT
}

\author{
Giuseppe Guglielmi, Daniele Chiarani, Devendra Prakash Saroj, Gianni Andreottola \\ Dipartimento di Ingegneria Civile e Ambientale, Università degli Studi di Trento \\ Via Mesiano, 77 - 38100 Trento (I) \\ giuseppe.guglielmi@ing.unitn.it \\ daniele.chiarani@ing.unitn.it \\ devendra.saroj@ing.unitn.it \\ gianni.andreottola@ing.unitn.it
}

\begin{abstract}
The physical properties of excess sludge wasted from a large pilot-scale membrane bioreactor (MBR) have been routinely monitored over almost two years. A statistical analysis highlighted the significant impact of temperature on the capillary suction time and sludge filterability, due to the increase of organic matter in the liquid phase. Suspended solids have resulted to be the most important component affecting sludge filterability, although the impact of colloids and solutes increased when temperature decrease, thus confirming the generally worse characteristics of sludge in such conditions. Conditioning and dewatering test have been performed on a pilot scale fixed volume recessed plate filter press. Six different chemicals were used for sludge pre-conditioning and, for each additive, three dosages were tested in the range $5 \div 25 \mathrm{~g}_{\text {polymer }} \mathrm{kgMLSS}^{-1}$. After about sixty filtration trials at three different pressure values $(7,11$ and 15 bar), the kind of polymer seem to be the most important factor influencing the final cake-dryness, with less evident impact for dosage and operational pressure. Finally, when performed on the aerobically digested excess sludge wasted from a conventional activated sludge plant, the filtration tests show no differences with the MBR sludge.
\end{abstract}

Key-words: MBR, sludge filterability, sludge dewaterability, EPS, TOC

\section{Introduction}

Since the introduction of submerged modules the membrane bioreactor technology has been extensively applied to both municipal and industrial wastewater treatment for its several advantages including effluent quality suitable for reuse, smaller footprint and lower sludge production compared with CASP (Conventional Activated Sludge Process). This has led to a considerable interest in the process by both academic researchers and practitioners: an easy survey on scientific search engines indicates that the number of items including the terms "membrane bioreactor" in the title and "wastewater" in the full text increased with an exponential trend during last 15 years, with its value doubled in the last three years [1]. So far, most of researches have been focused on understanding the mechanisms governing membrane fouling, with a special attention to the impact of membrane scouring aeration $[2,3,4]$, the effect of soluble microbial products and extracellular polymeric substances $[5,6,7]$ and the applicability of the critical flux concept for a more sustainable operation of the process $[8,9$, 10]. More recently a growing interest in the application of conventional activated sludge models ASM 1, ASM2d and ASM3 has spread throughout scientific community [11, 12, 13] aimed at predicting the performances of the process under various operational conditions which are in some cases extremely different than the typical ones of conventional activated sludge. In this field many efforts are focused on coupling biological process and fouling 
development in integrated model. On the other hand, since early applications one of the most appealing characteristics of the MBR technology has been represented by the possibility to reduce the surplus sludge production. In general terms, two categories of membrane bioreactor can be identified: in decentralised systems or in contexts where significant seasonal loading fluctuations are observed, long SRT operation is generally preferred due to the lack of facilities for excess sludge treatment and disposal. At the same time, the number of more "conventional" centralized MBR installations is constantly increasing, where sludge age values are just slightly higher than usual CASP thus resulting in a non-negligible amount of surplus sludge. Studies on the physical and rheological properties of surplus sludge from MBRs have been carried out mainly at bench and small pilot scale. Sludge dewaterability was found to be very close to that of conventional activated sludge, regardless with the increasing suspended solids $[14,15]$. Concerning the apparent viscosity, there is a common consensus on the non-Newtonian thixotropic behaviour of the MBR sludge and most studies indicate an increasing trend with the MLSS concentration, generally better fit by the Ostwald model [15, 16]. However, the interpretation about the actual impact of such higher viscosity on the energy demand of the process is still debated.

This paper reports results from almost 2 years operation of a large pilot scale plant which has been run in the framework of the EUROMBRA project. The behaviour of the excess sludge has been investigated in terms of filterability and dewaterability by means of conventional parameters (capillary suction time, CST; specific resistance to filtration, SRF, dilute sludge volume index, DSVI), content of carbohydrates, proteins and TOC. The experimental results presented here have been divided into two section: first, the outcomes of a statistical analysis are reported, aim at the assessment of the correlation between sludge properties and operational conditions such as process temperature. Then, the inferences from experimental trials on a pilot scale filterpress are presented, in which the actual dewatering potential of the sludge is evaluated, after conditioning with different chemicals and under various pressure values.

\section{Materials and methods}

A large pilot-scale MBR has been operated since Oct. 2006. The plant is located at the WWTP of Lavis (Trento, Italy) and is fed with pre-screened $(2 \mathrm{~mm})$ municipal wastewater pumped after the grit chamber of the full scale installations. The flow-diagram is shown in Fig. 1.

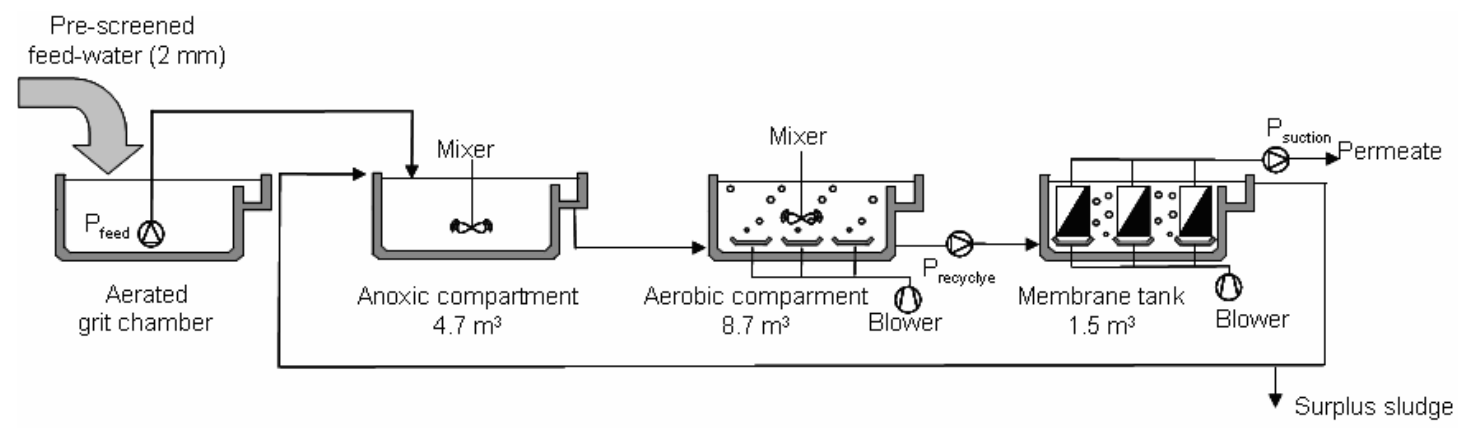

Fig. 1: Flow diagram of the large pilot scale MBR

The overall process volume is $14.9 \mathrm{~m}^{3}$, $10 \%$ of which being due to the membrane compartment in which three membrane modules (GE Zenon ZW500d) are immersed. The membrane material is a patented hydrophilicized PVDF, with a nominal pore size of $0.04 \mu \mathrm{m}$ and an overall membrane surface area of $\sim 100 \mathrm{~m}^{2}$. Both hydraulics- and biology-related 
parameters are monitored on-line including permeate flux, TMP, MLSS (in biotank and membrane chamber), dissolved oxygen and effluent ammonia and nitrate. After the transient phase at the plant start up, the system has been usually operated at a 20-25 days SRT (Solids Retention Time) which resulted in a pseudo steady state MLSS concentration of $6.8 \pm 0.9 \mathrm{~kg}$ $\mathrm{m}^{-3}$ and; being the recycle ratio in the range 3-4, the MLSS concentration in the membrane compartment was correspondingly between $8.3 \pm 1.0 \mathrm{~kg} \mathrm{~m}^{-3}$. Except for some specific experiments for the critical flux assessment (data not shown) the permeate flux has been tuned in the sub critical region, i.e. at values ranging between 10 and $20 \mathrm{~L} \mathrm{~m}^{-2} \mathrm{~h}^{-1}$. The influent wastewater characteristics have been monitored twice a week, by collecting 24 hours samples analysed according to the APHA Standard Methods [17]; the values for the main macropollutants are listed in Table 1.

Table 1: Composition of influent wastewater

\begin{tabular}{lcc}
\hline Parameter & Unit & Value \\
\hline COD & $\mathrm{g} \mathrm{m}^{-3}$ & $529.0 \pm 218.8$ \\
Soluble COD & $\mathrm{g} \mathrm{m}^{-3}$ & $127 \pm 81.0$ \\
TKN & $\mathrm{g} \mathrm{m}^{-3}$ & $66.3 \pm 42.0$ \\
$\mathrm{~N}^{-} \mathrm{NH}_{4}^{+}$ & $\mathrm{g} \mathrm{m}^{-3}$ & $39.7 \pm 22.2$ \\
Total P & $\mathrm{g} \mathrm{m}^{-3}$ & $7.8 \pm 5.1$ \\
TSS & $\mathrm{g} \mathrm{m}^{-3}$ & $294.3 \pm 276.0$ \\
VSS/TSS & $\%$ & $85.6 \pm 8.5$ \\
\hline
\end{tabular}

Sludge characteristics have been measured weekly for dewaterability, filterability and settleability. More in detail, on each sample of sludge collected from the wastage point (membrane tank) the following parameters have been determined:

- capillary suction time according to the APHA Standard Method 2710G with a portable apparatus (Triton 304B; chromatography paper Whatman no. 17)

$-\alpha \mathrm{C}\left(\mathrm{m}^{-2}\right)$ which is related to the specific resistance to filtration $\alpha$ and thus depends on the deposit properties and its built-up mechanism. $\alpha \mathrm{C}$ has been measured by means of unstirred dead end tests on polysulphone membrane (diameter: $47 \mathrm{~mm}$; pore size: $0.22 \mu \mathrm{m}$ ) at constant pressure $(0.5$ bar) with on-line registration of permeate volume (Sartorius Competence CP2202; one datum per second). The data collected have been elaborated according the Carman-Kozeny equation:

$$
\frac{t}{V}=\frac{\mu \cdot \alpha C \cdot V}{2 A^{2} \cdot P} \cdot V+\frac{\mu \cdot R_{m}}{A \cdot P}
$$

where $\mathrm{t}(\mathrm{s})$ is the time variable, $\mathrm{V}$ is the permeate volume $\left(\mathrm{m}^{3}\right), \mu$ is the dynamic viscosity of permeate $(\mathrm{Pa} \cdot \mathrm{s}), \alpha\left(\mathrm{m}^{-1} \mathrm{~kg}^{-1}\right)$ is the specific resistance to filtration and $\mathrm{C}\left(\mathrm{kg} \mathrm{m}^{-3}\right)$ is accumulated matter per unit of permeate volume, $\mathrm{A}$ is the membrane surface area $\left(\mathrm{m}^{2}\right), \mathrm{P}$ is the operational pressure $(\mathrm{Pa})$ and $\mathrm{R}_{\mathrm{m}}$ is the intrinsic membrane resistance $\left(\mathrm{m}^{-1}\right)$. For each sludge sample, three measurement have been carried out on different aliquots: (filtration 1) sludge itself, (filtration 2) supernatant after centrifugation (4000 g; 20 minutes), (filtration 3) supernatant after centrifugation of a sludge quote to which a $\mathrm{ZnSO}_{4}$ solution is added to flocculate colloids. The first $\alpha \mathrm{C}$ value accounts for all components in the sludge, the second for non settleable (colloidal matter) and solutes and the third one only for solutes. In this way, by assuming the additivity of resistances as proposed by [18], the $\alpha \mathrm{C}$ of solutes was determined by filtration 3 , the $\alpha \mathrm{C}$ of colloids as difference between filtration 2 and filtration $3, \alpha \mathrm{C}$ of suspended solids as difference between filtration 1 and filtration 2 .

- DSVI, according to the Standard Method 2710 D;

The content of proteins and polysaccharide has been weekly measured in the sludge. A centrifugation step (4000g, 10 minutes) and the supernatant filtration on a $1.5 \mu \mathrm{m}$ fibreglass filter have provided the sample for the suspended EPS. In turn, sludge pellets collected after 
the centrifugation have been resuspended in a buffer solution and subsequently added with a cationic exchange resin DOWEX $\left(80 \mathrm{~g}_{\text {resin }} \mathrm{g}_{\mathrm{Vss}}{ }^{-1}\right)$ and stirred at room temperature for 2 hours, in order to extract the polymeric substances bound to the floc structure. On such samples, proteins and carbohydrates have been measured assuming BSA and glucose as standard, respectively. Moreover, the TOC content was determined on the same samples with cuvette test HACH-LANGE LCK385; these samples are also referred to as TOC in free EPS (TOC$\mathrm{EPS}_{\mathrm{f}}$ ) and TOC in bound EPS (TOC-EPS ${ }_{\mathrm{b}}$ ).

Statistical analysis of the data from long term operation has been carried out to explore various interrelations among observed parameters. All the statistical analyses have been executed with the TANAGRA, a free data mining software for academic and research purposes which offers several data mining methods from exploratory data analysis, statistical learning, machine learning and databases area [19]. The Pearson's correlation has been used for the analysis and interpretation; the correlation coefficients always lie between -1 and +1 showing perfectly negative correlation at -1 and perfectly positive correlation at +1 respectively. A value of correlation coefficient makes sense for showing a positive or negative correlation when the absolute value is more than the critical value depending upon sample size and the confidence interval (usually 95\%); e.g. when the sample size is larger than 60, values of correlation coefficients higher than 0.254 (or lower than -0.254 towards -1 ) start showing increasing significance [20].

A pilot scale fixed volume recessed plate filter press (Fraccaroli \& Balzan, FB 300/1) has been used for the dewatering tests on chemically conditioned sludge. The equipment consist of two plates forming a filtration chamber $(0.3 \mathrm{~m} \times 0.3 \mathrm{~m} \times 0.024 \mathrm{~m}$; chamber volume

$0.0021 \mathrm{~m}^{3}$ ), with a dedicate membrane pump feeding the pre-conditioned sludge. Six different commercial structured and linear polymers have been used for sludge pre-conditioning at different dosages, in a range between 5 and $25 \mathrm{~g}_{\text {polymer }} \mathrm{kgMLSS}^{-1}$, once prepared a $0.5 \%$ solution (w/w). Trials have been carried out at three different operational pressure $(7,11$ and 15 bar) with a test duration of two hours. At the end of each trial, samples were collected from both the outer and central part of the dewatered sludge cake, in order to have a representative average sample.

\section{Results}

\subsection{Statistical analysis}

The trends of MLSS, CST, the $(\alpha \mathrm{C})_{\text {sludge }}$ (i.e. the $\alpha \mathrm{C}$ of sludge itself), DSVI, temperature and TOC over the experimental period are plotted in Fig. 2. Concerning the MLSS concentration, after the start up a quasi steady state value was reached which was constantly kept except for a sudden but indeed curbed sludge leakage on July 2007. Dewaterability, filterability and settleability were fairly good, though being somehow affected by the temperature. A further comprehension of such aspects is possible by considering the results of the statistical analysis (Table 2). The Pearson's correlation coefficients indicate that temperature plays a significant role on all the three key parameters describing sludge characteristics viz. CST, $(\alpha \mathrm{C})_{\text {sludge }}$ and DSVI; all these quantities are negatively correlated with temperature. Noticeably, bound form of EPS (expressed as TOC) correlates positively whereas the free form tends to correlate negatively. On the whole, the TOC related to total extracted EPS (free + bound) correlates positively with temperature, meaning thereby higher production of organic compounds at higher temperature. This observation apparently differs from analysis reported by [21] where the method of extraction and mode of measurement (as TOC or as Carbohydrates and Proteins) are different. Also [22] commented that high EPS causes high viscosity and accumulation on the membrane surface leading to increase in the filtration resistance. On 
account of such diversified inferences supported from various methods of analysis and different definitions of EPS fractions, the comparison of outcomes is rather difficult as also stated by [23]. However, all these works agree on indicating the negative effect of temperature on the content of organic foulants in the liquid phase, that is also confirmed by other researches in which seasonal fluctuations of membrane permeability and critical flux are reported [inter alia 6,9$]$.
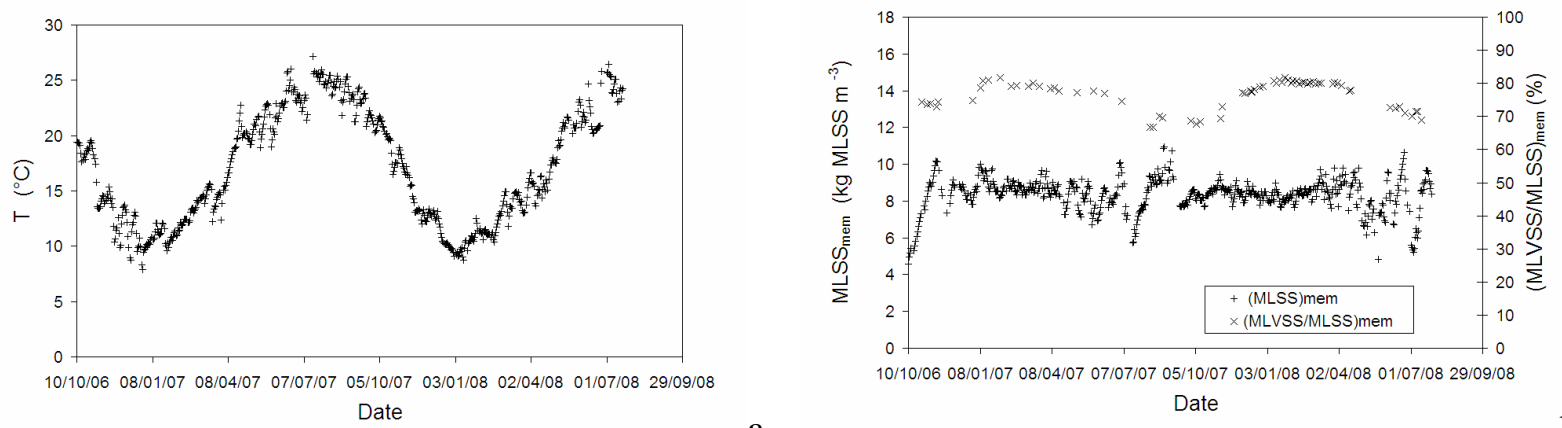

a
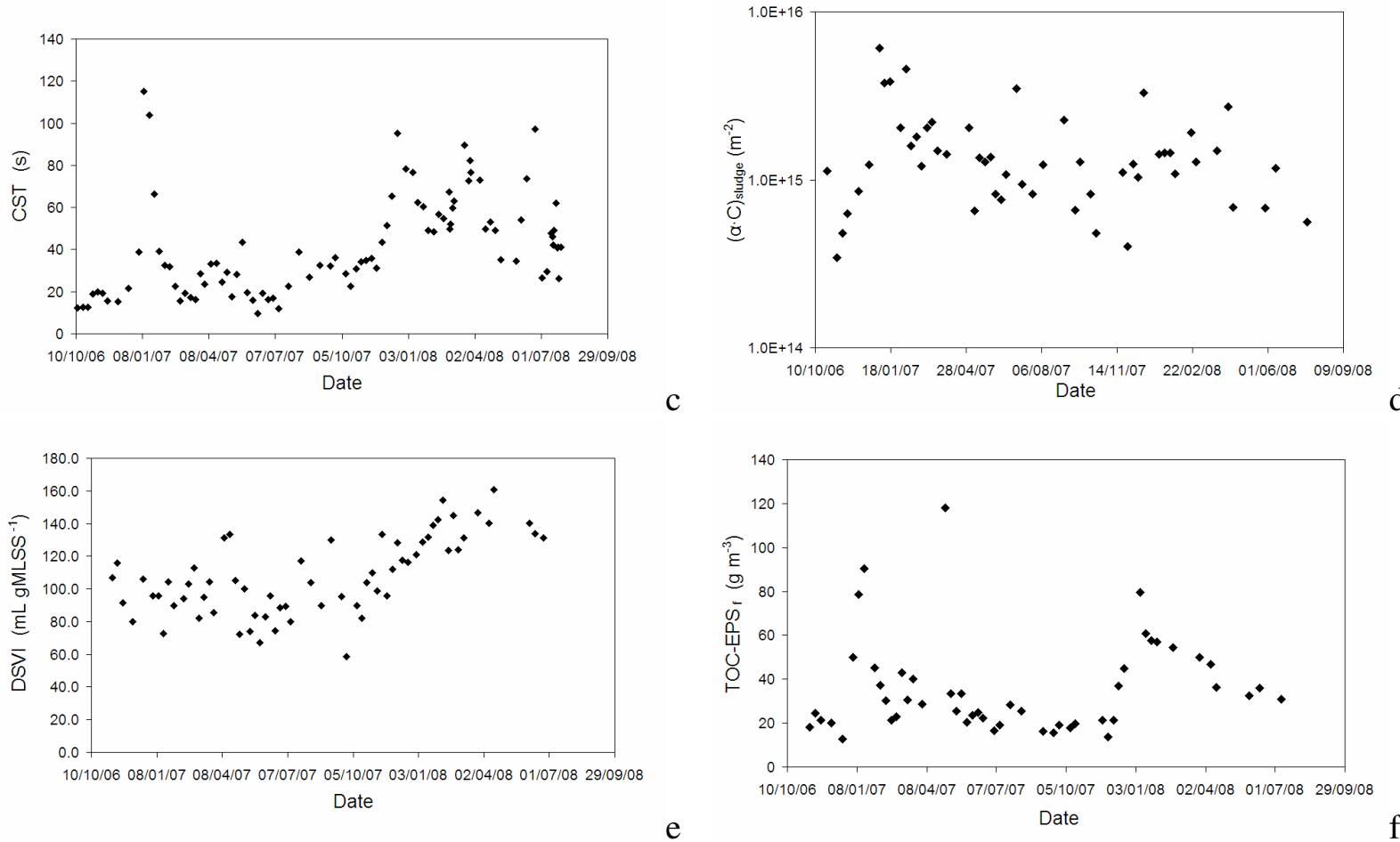

Fig. 2: Profile of monitored parameters in the surplus sludge: (a) sludge temperature, (b) MLSS and (MLVSS/MLSS) ratio, (c) capillary suction time, $(\mathrm{d})(\alpha \mathrm{C})$ sludge, (e) DSVI, (f) TOC related to free EPS

The positive correlation of TOC content in free EPS with sludge characteristics indicators $\left(\mathrm{CST},(\alpha \mathrm{C})_{\text {sludge }}\right)$ approves the role free EPS in filtration behaviour. Combining the effect of temperature and EPS on CST, $(\alpha \mathrm{C})_{\text {sludge }}$ and DSVI, it can be argued that higher EPS-organics at higher temperature should lead to poor dewaterability and filterability as contrary to the observation (CST, $(\alpha \mathrm{C})_{\text {sludge }}-\mathrm{T}$ correlation). This should be given further attention as the major component of EPS (as TOC) is of bound form, while free form correlates opposite which presumably impacts directly on CST and $(\alpha \mathrm{C})_{\text {sludge }}$; this analysis becomes more clear from the positive correlation of CST and $(\alpha \mathrm{C})_{\text {sludge }}$ with free EPS, while they show no correlation with 
bound or total EPS (as TOC). Furthermore, inferences [24] could be relevant here suggesting that high (bound and total) EPS concentration leads to larger flocs buffering the shear force between flocs and it prevents deflocculation which in turn improves the filterability. Moreover, the poor correlation of both bound and free proteins and carbohydrates with sludge physical properties seems to suggest other organics (such as humics) to play a major role on sludge dewaterability and filterability in this case.

Table 2: Pearson's correlation coefficients pertaining to sludge properties

\begin{tabular}{lccccccccc}
\hline $\begin{array}{l}\text { Parameters } \rightarrow \\
\downarrow\end{array}$ & TOC-EPS & TOC-EPS & CST & $(\boldsymbol{\alpha C})_{\text {sludge }}$ & $(\boldsymbol{\alpha C})_{\text {sol+coll }}$ & DSVI & T & MLSS \\
\hline TOC-EPSf & 1 & 0.207 & $0.656^{*}$ & $0.483^{*}$ & $0.670^{*}$ & $-0.295^{*}$ & -0.237 & 0.266 \\
TOC-EPSb & 0.207 & 1 & -0.169 & -0.247 & -0.124 & 0.082 & $0.455^{*}$ & 0.048 \\
CST & $0.656^{*}$ & -0.169 & 1 & $0.536^{*}$ & $0.658^{*}$ & $0.437^{*}-0.436^{*}$ & 0.236 \\
$(\boldsymbol{\alpha C})_{\text {sludge }}$ & $0.483^{*}$ & -0.247 & $0.536^{*}$ & 1 & $0.309^{*}$ & -0.140 & $-0.435^{*}$ & 0.128 \\
$(\boldsymbol{\alpha C})_{\text {sol+coll }}$ & $0.670^{*}$ & -0.124 & $0.658^{*}$ & $0.309^{*}$ & 1 & -0.090 & $-0.580^{*}$ & 0.145 \\
$\mathbf{D S V I}$ & $-0.295^{*}$ & 0.082 & $0.437^{*}$ & -0.140 & -0.090 & 1 & $-0.332^{*}$ & $0.291^{*}$ \\
$\mathbf{T}$ & $-0.337^{*}$ & $0.455^{*}$ & $-0.436^{*}$ & $-0.435^{*}$ & $-0.580^{*}$ & $-0.332^{*}$ & 1 & -0.238 \\
$\mathbf{M L S S}$ & 0.266 & 0.048 & 0.236 & 0.128 & 0.145 & $0.291^{*}$ & -0.238 & 1 \\
\hline
\end{tabular}

* Significant correlation at 0.05 level (2-tailed)

The $(\alpha \mathrm{C})_{\text {sludge }}$ correlates positively with CST, as expected; its dependency with Temperature and EPS is mostly similar to that with CST. Noticeably, while CST correlates with DSVI, the $(\alpha \mathrm{C})_{\text {sludge }}$ does not; the correlation of free EPS (as TOC) with $(\alpha \mathrm{C})_{\text {sludge }}$ is weaker than that with CST. The impact of solutes, colloids and suspended solids on the $(\alpha \mathrm{C})_{\text {sludge }}$ is shown in Fig. 3: in agreement with [25], once reached the steady state conditions the suspended matter resulted to be the most relevant factor affecting filterability, although a clear increase of the impact of solutes was observed at lowest temperature, when also CST showed a sudden increase.

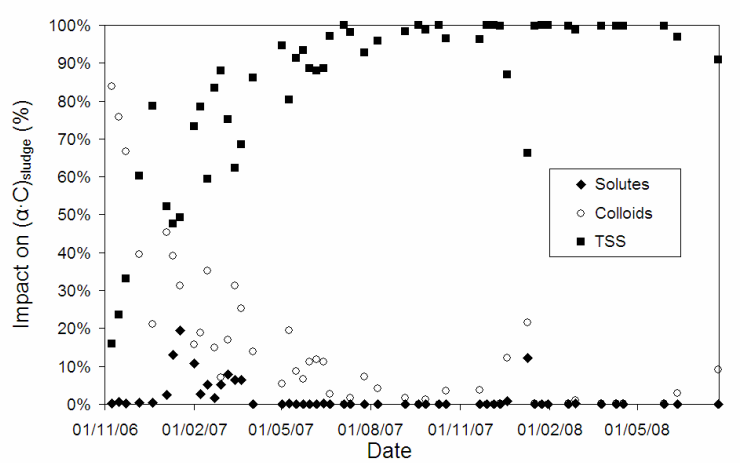

Fig. 3: Percent role of solutes, colloids and suspende solids on the $(\alpha \mathrm{C})_{\text {sludge }}$

The DSVI positively correlates with CST indicating that the filtration behaviour might as well be associated with the settling behaviour; this infers that sludge with good settleability should 
show better ease to filtration, however, no correlation with $(\alpha \mathrm{C})_{\text {sludge }}$ puts ambiguity in accepting DSVI as relevant parameters with reference to filtration behaviour understanding. The MLSS is not well correlated with any of the parameters mentioned in Table 2; a weak positive correlation with DSVI and free EPS (as TOC) can be attributed to extracellular organic materials influencing the settling behaviour at higher MLSS. Few researches $[22,26]$ commented that filtration resistance increases with increase in MLSS; and more recent researches [21, 27, 28] suggest that MLSS can possibly correlate with fouling/filtration related parameters only at very high concentrations.

\section{$3.2 \quad$ Filter-press tests}

Some 60 dewatering tests were performed over the whole experimental period, under steady state sludge age. The behaviour of the different chemicals dosed at different pressure values are summarised in Fig. 4.
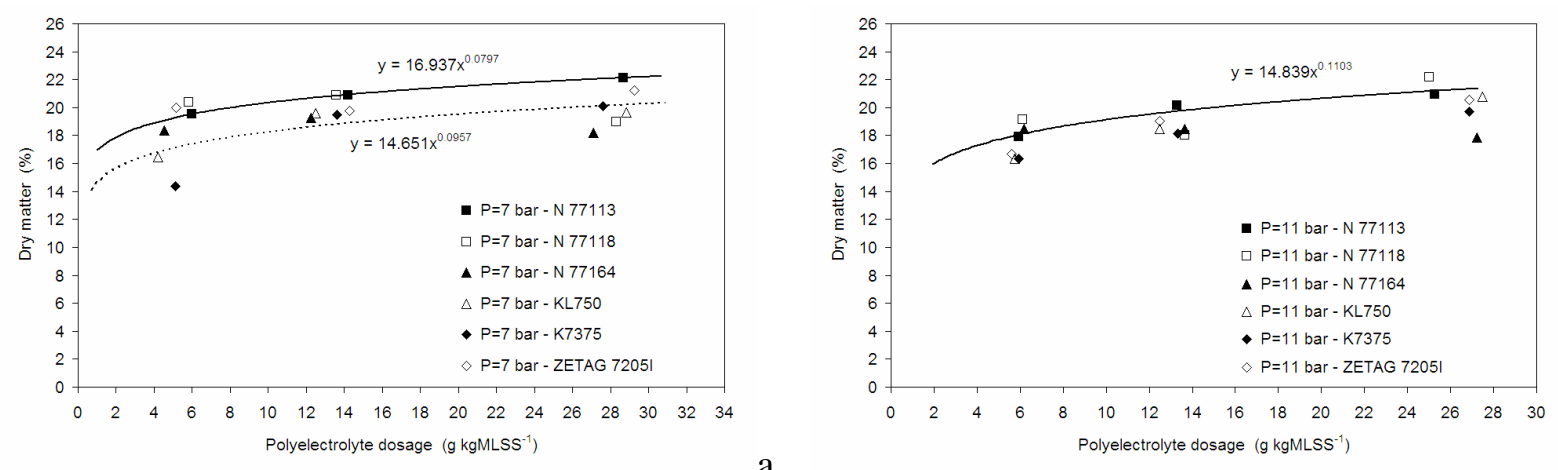

a
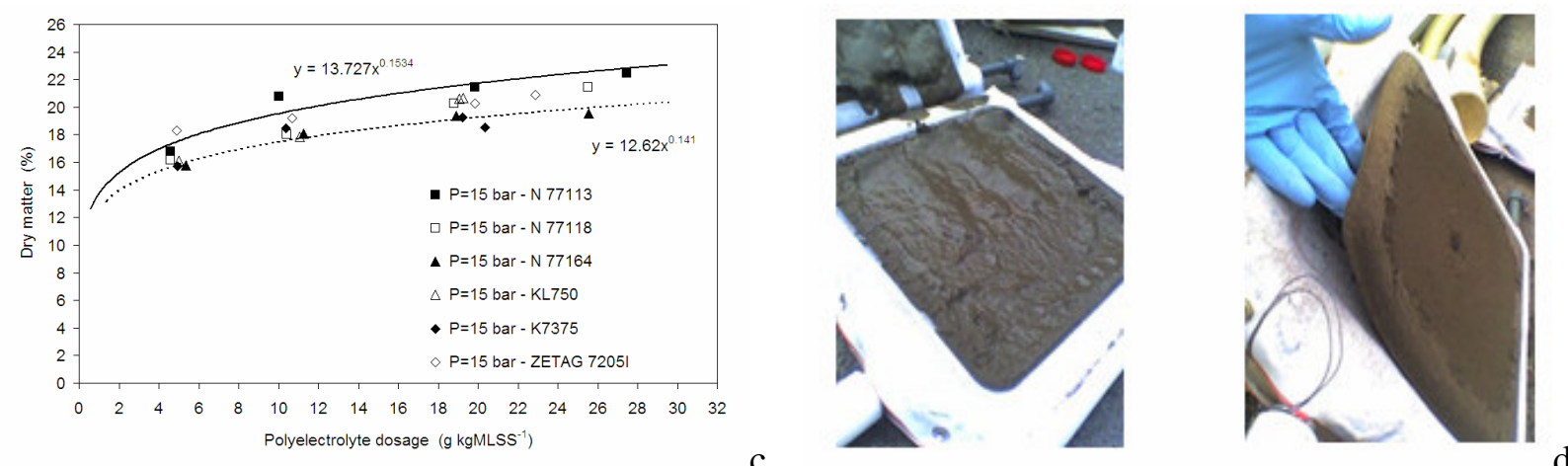

c

Fig. 4: Average dry matter content at the end of the dewatering tests with the different chemicals used. Trials at 7, 11 and 15 bars are reported in graphs a, b and c respectively. In box $d$ cakes obtained without (left) and with (right) sludge pre-conditioning are shown.

Visual inspection confirmed the crucial role of sludge conditioning (see Fig. 4 d). However, regardless with the type of polymer used, dosage seemed to cause a minor impact on the final dry matter content, which is generally well described by a power-law. In order to ensure the sludge fed to the filter-press does not change its dewaterability propensity, the capillary suction time was routinely measured at regular intervals. Over the whole experiments performed, the DM\% ranged between 14 and 24\%, with better results for the liquid structured polymer N 77113 and the powder acrilamide cationic polymer ZETAG 7205I. The values obtained are lower than those reported in technical literature for filter press devices [29] which, however, are mostly referred to combined sludge conditioning with lime and polymers. Furthermore, the results obtained during some spot tests performed with ZETAG 
7205I and N77113 on sludge samples collected from the aerobic digestion compartment of the full scale municipal wastewater treatment plant in Lavis seem to suggest there are no differences between the conventional activated sludge and the MBR sludge when in the same range of sludge age. The Lavis WWTP is a CASP for denitrification and nitrification and it is operated at a sludge age of $\sim 15$ days; the additional SRT in the aerobic stabilisation tank is 10 days and the sludge is usually dewatered by means of a belt-press device. Compared with the surplus sludge of the membrane bioreactor, trials carried out at 11 and 15 bar on samples of surplus sludge collected from the aerobic digestion of the full scale CASP plant (MLSS 10 $\mathrm{kg} \mathrm{m}^{-3}$ ) gave even slightly lower values of dry matter content with the same polymer and in the same range of polyelectrolyte dosage (15-20\%).

\section{Conclusions}

Surplus sludge sample have been collected from a large pilot scale MBR and analysed in terms of dewaterability, filterability and settleability over an experimental period of almost two years. The three physical properties have been found to be negatively correlated with to temperature, with increasing values at lower temperatures; this is probably to be ascribed to the higher content of organics in the liquid phase which also affects the role of colloids and solutes on the overall sludge filterability.

Tests carried out on a pilot scale filter press compared the effect of different operational pressures, chemicals and dosage on the dry matter content after 2-hours filtration tests. The results pointed out the major role of polymer in influencing the final moisture of the cake, with no significant variations at different dosages and pressures; a powder cationic acrilamide-based polymer and a structural polymer in liquid form were proven to achieve the best dewatering performances.

\section{Acknowledgement}

The authors acknowledge the EU-funded EUROMBRA project (018480-FP $6^{\text {th }}$ Global Change and Ecosystems) for the financial support.

\section{References}

[1] www.scirus.com, accessed on $27^{\text {th }}$ August 2008

[2] F. Meng, F. Yang, B. Shi, M. Zhang, Sep. Pur. Tech., 59 (1), (2008), 91-100

[3] J.-K. Kim, I.-S. Chang, D.-H. Shin, H.-H. Park, Des., 231 (1-3), (2008), 35-43

[4] J.A. Howell, H.C. Chua, T.C. Arnot, J. Membr. Sci., 218 (1-2), (2004), 13-19

[5] S. Arabi, G. Nakhla, J. Membr. Sci., 324 (1-2), (2008), 142-150

[6] S. Lyko, T. Wintgens, D. Al-Halbouni, S. Baumgarten, D. Tacke, K. Drensla, A. Janot, W. Dott, J. Pinnekamp, T. Melin, J. Membr. Sci., 317 (1-2), (2008), 78-87

[7] S. Rosenberger, C. Labs, B. Lesjean, R. Gnirss, G. Amy, M. Mekel, J.-C. Schrotter, Wat. Res., 40 (4), (2006), 710-720

[8] G. Guglielmi, D. Chiarani, S.J. Judd, G. Andreottola, J. Membr. Sci., 289 (1-2), (2007), 241-248

[9] G. Guglielmi, D.P. Saroj, D. Chiarani, G. Andreottola, Wat. Res., 41 (17), (2008), 39033914

[10] F. Fan, H. Zhou, H. Husain, Wat. Res., 40 (2), (2006), 205-212

[11] G. Di Bella, G. Mannina, G. Viviani, J. Membr. Sci., 322 (1), (2008), 1-12

[12] M. Spérandio, M.C. Espinosa, Des., 231 (1-3), (2008), 82-90

[13] T. Wintgens, J. Rosen, T. Melin, C. Brepols, K. Drensla, N. Engelhardt, J. Membr. Sci., 216 (1-2), (2003), 55-65 
[14] W. Khongnakorn, C. Wisniewski, L. Pottier, L. Vachoud, Sep. Pur. Tech., 55, (2007), 125-131

[15] A. Pollice, C. Giordano, G. Laera, D. Saturno, G. Mininni, Wat. Res., 41 (8), (2007), $1832-1840$

[16] S. Rosenberger, K. Kubin, M. Kraume, M., Eng. Life Sci., 9, (2002), 269-275

[17] APHA-Standard methods. $19^{\text {th }}$ Edition. American Public Health Association, Washington, DC, 1995

[18] E.H. Bouhabila, R. Ben Aim, H. Buisson, Des., 118 (1-3), (1998), 315-322

[19] R. Rakotomalala, Proceedings of EGC-2005, RNTI-E-3, Vol. 2, (2005), 697-702(in

French)

[20] J.H. Wilson, Essential Statistics, Prentice Hall Publication, 2005

[21] Z. Wu, Z. Wang, Z. Zhou, G. Yu, G. Gu, Des., 212 (1-3), (2007), 152-164

[22] H. Nagaoka, S. Ueda, A. Miya, Wat. Sci. Technol., 34 (9), (1996), 165-172

[23] S. Rosenberger, H. Evenblij, S.T. Poele, T. Wintgens, C. Laabs, J. Membr. Sci., 263 (12), (2005), 113-126

[24] X.Y. Li, Y. Yuan, H.W. Wang, Environ. Sci. Technol., 37 (2), (2003), 292-299

[25] C. Wisniewski, A. Grasmick, A., Med. Fac. Laundbow Univ. Gent, 61 (4b), (1996), 2017-2024

[26] Y. Shimizu, Y. Okuno, K. Uryu, S. Ohtsubo, A. Watanabe, Wat. Res., 30 (10), (1996), 2385-2392

[27] S. Rosenberger, M. Kraume, Des., 151 (2), (2003), 195-200

[28] S.P. Hong, T.H. Bae, T.M. Tak, S. Hong, A. Randall, A., Des., 143 (3), (2002), 219-228

[29] Metcalf \& Eddy, Wastewater Engineering: treatment and reuse - 4th Edition, McGrawHill, 2003 